\title{
Spontaneous Pneumothorax as a Complication in Concomitant Diabetic Ketoacidosis and Pulmonary Tuberculosis: A Case Report
}

\author{
Filbert Riady Adlar ${ }^{a}$ Willy Anthony \\ aRSUD Beriman Balikpapan, Balikpapan, Indonesia; 'bepartment of Internal Medicine, \\ RSUD Beriman Balikpapan, Balikpapan, Indonesia
}

\section{Keywords}

Secondary spontaneous pneumothorax . Diabetic ketoacidosis $\cdot$ Pulmonary tuberculosis

\begin{abstract}
Secondary spontaneous pneumothorax (SSP) can occur as a complication of several underlying diseases such as pulmonary tuberculosis (TB) or, rarely, diabetic ketoacidosis (DKA). As diabetes mellitus (DM) is significantly prevalent in tuberculosis patients, it is possible to have both TB and DKA concurrently. However, there has not been any documentation of SSP as a complication in concomitant DKA and pulmonary TB. In this report, we described a 30-year-old female who presented to the emergency department with a chief complaint of shortness of breath that had intensified since a day before. She was diagnosed with pulmonary TB 1 week before and had started on her anti-tuberculosis drugs regimen. Prior history of DM was not known. Physical examination showed a slight decrease in consciousness, tachycardia, tachypnea, Kussmaul breathing, decreased lung sounds in the right hemithorax and hyperresonant on percussion. Laboratory results showed leukocytosis and hyperglycemia, ketones were positive on urinalysis and arterial blood gas analysis indicated metabolic acidosis. Chest X-ray revealed pneumothorax in the right hemithorax. She was diagnosed with pneumothorax of the right hemithorax, DKA, sepsis and pulmonary TB. Treatment involved prompt placement of chest tube drainage, fluid rehydration, intravenous insulin, antibiotic, sodium bicarbonate and
\end{abstract}




\section{Case Reports in Acute Medicine}

Case Rep Acute Med 2021;4:7-12

\begin{tabular}{l|l}
\hline DOI: 10.1159/000513324 & $\odot 2021$ The Author(s). Published by S. Karger AG, Basel
\end{tabular} www.karger.com/cra

Adlar and Anthony: Spontaneous Pneumothorax as a Complication in Concomitant Diabetic Ketoacidosis and Pulmonary Tuberculosis: A Case Report

anti-tuberculosis drugs. Her condition improved after 9 days of uneventful hospitalization. We discussed how concomitant presence of both DKA and pulmonary TB can increase the likelihood of developing secondary spontaneous pneumothorax.

\section{Introduction}

Secondary spontaneous pneumothorax (SSP) is a life-threatening condition that can occur as a complication of various diseases such as pulmonary tuberculosis (TB) and diabetic ketoacidosis (DKA). The incidence of SSP due to pulmonary TB is uncommon; about 0.95$1.5 \%$ of active pulmonary TB patients develop SSP $[1,2]$. Meanwhile, SSP due to DKA was only documented in a few case reports $[3,4]$. DKA and pulmonary TB can occur simultaneously, as diabetes mellitus (DM) is a significant comorbidity in pulmonary TB cases [5]. DKA and pulmonary TB have distinct mechanisms to induce pneumothorax and when both diseases are present concurrently, they can potentially increase the likelihood of developing SSP. Here, we report a presentation of secondary pneumothorax as a complication in concomitant DKA and pulmonary TB.

\section{Case Presentation}

A 30-year-old female presented to our emergency department with shortness of breath that had intensified since a day before. Accompanying symptoms include cough and loss of weight. About 1 week before, she was diagnosed with pulmonary TB at her primary health care center with a positive acid-fast bacilli sputum result and had commenced her anti-tuberculosis drugs regimen. Prior history of DM was not known.

Physical examination showed a decrease in consciousness with a Glasgow Coma Scale of 14 (E3, V5, M6), blood pressure of 100/70 mm Hg, tachycardia of 140 beats/min, tachypnea of 40 breaths/min with a Kussmaul breathing pattern. Oxygen saturation was recorded to be $98 \%$ with supplementation of oxygen at $8 \mathrm{~L} / \mathrm{min}$ using non-rebreathing mask. Chest expansion and breath sounds were reduced in the right hemithorax and was hyperresonant upon percussion.

Laboratory examination showed leukocytosis $(20,910$ cells $/ \mu \mathrm{L})$ with a differential count of $86 \%$ segmented neutrophils, hyperglycemia (plasma blood glucose of $776 \mathrm{mg} / \mathrm{dL}$ ), serum sodium concentration of $147 \mathrm{mmol} / \mathrm{L}$, serum potassium concentration of $5.1 \mathrm{mmol} / \mathrm{L}$, serum chloride of $109 \mathrm{mmol} / \mathrm{L}$, serum urea of $49 \mathrm{mg} / \mathrm{dL}$ and creatinine of $1.34 \mathrm{mg} / \mathrm{dL}$. Serum albumin was $3.4 \mathrm{~g} / \mathrm{dl}$ and the anion gap was calculated to be $50.6 \mathrm{mmol} / \mathrm{L}$. Regrettably, serum lactate examination was unavailable in our facility. Ketones $(+3)$ and glucose $(+4)$ were both strongly positive on dipstick urinalysis. The arterial blood gas analysis result indicated metabolic acidosis with a pH of 7.15, $\mathrm{PCO}_{2}$ of $13.9 \mathrm{~mm} \mathrm{Hg}, \mathrm{HCO}_{3}-$ of $4.9 \mathrm{mmol} / \mathrm{L}$ and base excess of $-24 \mathrm{mmol} / \mathrm{L}$. Chest X-ray revealed the presence of air in the right pleural space (avascular region) and the collapsed right lung parenchyma (Fig. 1). Our center's radiologist also noted the presence of an inhomogeneous opacity in the upper lobe of the right lung.

Diagnoses of pneumothorax of the right hemithorax, DKA, sepsis and pulmonary TB were established. Treatment involved an immediate placement of chest tube drainage to the right hemithorax by a pulmonologist, rehydration with normal saline, administration of

\section{Karger'=}




\section{Case Reports in Acute Medicine}

intravenous insulin following the Yale Insulin Infusion Protocol, [6] levofloxacin $750 \mathrm{mg}$ s.i.d, correction of acidosis with sodium bicarbonate and continuation of anti-tuberculosis drugs regimen. The patient was admitted to the isolation intensive care unit (ICU) ward. Subsequent chest X-ray was obtained (Fig. 2), directly following chest tube drainage placement. On evaluation, there was a reduction in the size of the pneumothorax. The patient gradually experienced improvement in symptoms and became clinically stable. She was hospitalized in the ICU for 3 days before she was transferred to the isolation ward and stayed there for a further 6 uneventful days before being discharged.

\section{Discussion/Conclusion}

Pneumothorax due to DKA has only been reported in a few case reports [3, 4]. It was hypothesized that Kussmaul breathing or prolonged vomiting increases intra-alveolar pressure, which resulted in alveolar rupture [3, 4, 7]. Kussmaul respiration can elevate the intra-alveolar pressure by 20-30 mm Hg [7]. Apart from pneumothorax, other possible mechanicallyinduced complications arising from the same underlying mechanism of DKA are pneumomediastinum, $[3,4,7,8]$ and pneumopericardium [3]. Whilst it is still unclear whether Kussmaul breathing or prolonged vomiting plays a bigger role, it has been reported that both were seen independently causing these complications [7]. There was no report of prolonged vomiting in our patient; however, Kussmaul breathing was evident.

Secondary spontaneous pneumothorax due to pulmonary TB is relatively uncommon [1, 2]. SSP develops from bronchopleural fistulas or cavitation of pulmonary parenchyma that extends to the pleural space following initial caseous necrosis of the Mycobacterium tuberculosis infection $[9,10]$. In particular, SSP was reported to be strongly associated to cavitary pulmonary TB lesions [10]. Interestingly, pulmonary TB cases with DM were associated with cavitary lesions at presentation more than in pulmonary TB without DM [11]. Although the pathogenesis of lung cavities in pulmonary TB is yet to be clearly elucidated, a widely regarded understanding involves liquefaction of necrotic core in the granuloma followed by drainage to the bronchial airway and expulsion through coughing $[12,13]$. Lung cavities due to pulmonary TB tend to develop in areas with high mechanical stress, such as the apex, and were frequently located within the subpleural region [14]. Hence, the infection can easily extend to the pleural space. Unfortunately, our patient did not have a previous chest X-ray, but there was inhomogeneous opacity in the upper lobe of the right lung on initial chest X-ray.

We postulate that concomitant presence of both DKA and pulmonary TB increases the likelihood of developing SSP. This conceptual framework is based on several aspects. Firstly, apart from subpleural localization, lung cavities have fibrotic external shell, which is less elastic and thus more susceptible to tensile force. This structural vulnerability can predispose the rupture of cavity; however, cavities do not naturally rupture [14]. Secondly, therefore, we think that a precipitating factor is required to induce pneumothorax through rupture of the pulmonary cavity. Briones-Claudett et al. [15] have recently depicted a case of SSP likely due to the rupture of a cavity in a pulmonary TB patient. In that specific report, pulmonary bacterial co-infection was noted and this might suggest the role of bacterial co-infection as a precipitating factor for SSP in pulmonary TB. In our case, we think that the precipitating factor is the Kussmaul breathing. Thirdly, we would like to address the biomechanical nature of this hypothesis. The law of Laplace states that wall tension of a spherical structure is directly proportional to the pressure within it and the radius of the sphere, and inversely proportional to

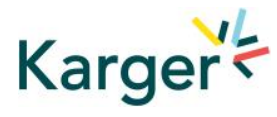




\section{Case Reports in Acute Medicine}

\begin{tabular}{l|l}
\hline Case Rep Acute Med 2021:4:7-12 \\
\hline DOI: 10.1159/000513324 & $\begin{array}{l}\text { @ 2021 The Author(s). Published by S. Karger AG, Basel } \\
\text { www.karger.com/cra }\end{array}$ \\
\hline
\end{tabular}

Adlar and Anthony: Spontaneous Pneumothorax as a Complication in Concomitant Diabetic Ketoacidosis and Pulmonary Tuberculosis: A Case Report

the width of its wall [16]. Pressure within the cavity would increase from Kussmaul breathing due to the bronchial communication of the cavities. However, not all cavities have persisting bronchial connection [14]. Increased pressure results in escalation of wall stress and eventual rupture of the vulnerable cavity. Ultimately, further research is warranted to explore the proposed pathophysiology.

Pulmonary TB and DM negatively influence each other $[11,17]$. The World Health Organization (WHO) recommends to screen for TB symptoms in diabetics and to screen for DM in TB patients [18]. In our case, it was unclear if the patient was previously screened for DM. Early detection and prompt treatment of DM and tuberculosis can prevent the development of complications, such as DKA and SSP, which would lead to better outcomes.

To our knowledge, this is the first case reporting spontaneous pneumothorax as a complication in concurrent DKA and pulmonary TB. We examined the distinct pneumothorax-inducing mechanism in DKA and pulmonary TB, and highlighted a potential synergistic effect that is not generally known. The limitations of this case report include the lack of objective measurement of pneumothorax, lack of lactate measurement, and there was no previous chest $\mathrm{X}$-ray performed on the patient prior to presentation at our emergency department.

\section{Statement of Ethics}

The authors have no ethical conflicts to disclose. A written informed consent was obtained from the patient for the publication of this case report and relevant images.

\section{Conflict of Interest Statement}

The authors have no conflicts of interest to declare.

\section{Funding Sources}

The authors have no funding sources to disclose.

\section{Author Contributions}

F.R.A. wrote the original draft. W.A. revised the draft. Both authors were involved in the conceptualization and analysis of the work before reaching mutual final agreement of the work to be published.

\section{References}

1 Freixinet JL, Caminero JA, Marchena J, Rodríguez PM, Casimiro JA, Hussein M. Spontaneous pneumothorax and tuberculosis: long-term follow-up. Eur Respir J. 2011 Jul;38(1):126-31.

2 Aktoğu S, Yorgancioglu A, Çırak K, Köse T, Dereli ŞM. Clinical spectrum of pulmonary and pleural tuberculosis: a report of 5,480 cases. Eur Respir J. 1996 Oct;9(10):2031-5.

\section{Karger'=}




\section{Case Reports in Acute Medicine}

\begin{tabular}{l|l}
\hline Case Rep Acute Med 2021:4:7-12 \\
\hline DOI: 10.1159/000513324 & $\begin{array}{l}\text { ○ 2021 The Author(s). Published by S. Karger AG, Basel } \\
\text { www.karger.com/cra }\end{array}$ \\
\hline
\end{tabular}

Adlar and Anthony: Spontaneous Pneumothorax as a Complication in Concomitant Diabetic Ketoacidosis and Pulmonary Tuberculosis: A Case Report

3 Pereira 0, Baburaj R, Abraham P. Spontaneous pneumomediastinum and pneumopericardium: a rare complication of diabetic ketoacidosis: No. 38 in a regular educational series of brief illustrated descriptions of interesting or unusual diabetes-related cases and conditions. Pract Diabetes Int. 2004 0ct;21(8):300b300b.

4 Weathers LS, Brooks WG, DeClue TJ. Spontaneous pneumomediastinum in a patient with diabetic ketoacidosis: a potentially hidden complication. South Med J. 1995 Apr;88(4):483-4.

5 Noubiap JJ, Nansseu JR, Nyaga UF, Nkeck JR, Endomba FT, Kaze AD, et al. Global prevalence of diabetes in active tuberculosis: a systematic review and meta-analysis of data from $2 \cdot 3$ million patients with tuberculosis. Lancet Glob Health. 2019 Apr;7(4):e448-60.

6 Goldberg PA, Siegel MD, Sherwin RS, Halickman JI, Lee M, Bailey VA, et al. Implementation of a safe and effective insulin infusion protocol in a medical intensive care unit. Diabetes Care. 2004 Feb;27(2):461-7.

7 Pooyan P, Puruckherr M, Summers JA, Byrd RP Jr, Roy TM. Pneumomediastinum, pneumopericardium, and epidural pneumatosis in DKA. J Diabetes Complications. 2004 Jul-Aug;18(4):242-7.

8 Steenkamp D, Patel V, Minkin R. A Case of Pneumomediastinum: A Rare Complication of Diabetic Ketoacidosis. Clin Diabetes. 2011 Apr;29(2):76-7.

9 Borrego Galán JC, Rivas López P, Remacha Esteras MA. [Recurrent tuberculous pneumothorax and tuberculous empyema: an association of two rare complications]. Arch Bronconeumol. 2003 Oct;39(10):478-9.

10 Shamaei M, Tabarsi P, Pojhan S, Ghorbani L, Baghaei P, Marjani M, et al. Tuberculosis-associated secondary pneumothorax: a retrospective study of 53 patients. Respir Care. 2011 Mar;56(3):298-302.

11 Restrepo BI. Diabetes and Tuberculosis. Microbiol Spectr. 2016 Dec;4(6). https://doi.org/10.1128/microbiolspec.TNMI7-0023-2016.

12 Hunter RL. Tuberculosis as a three-act play: A new paradigm for the pathogenesis of pulmonary tuberculosis. Tuberculosis (Edinb). 2016 Mar;97:8-17.

13 Ong CW, Elkington PT, Friedland JS. Tuberculosis, pulmonary cavitation, and matrix metalloproteinases. Am J Respir Crit Care Med. 2014 Jul;190(1):9-18.

14 Ihms EA, Urbanowski ME, Bishai WR. Diverse Cavity Types and Evidence that Mechanical Action on the Necrotic Granuloma Drives Tuberculous Cavitation. Am J Pathol. 2018 Jul;188(7):1666-75.

15 Briones-Claudett KH, Briones-Claudett MH, Posligua Moreno A, Estupiñan Vargas D, Martinez Alvarez ME, Grunauer Andrade M. Spontaneous Pneumothorax After Rupture of the Cavity as the Initial Presentation of Tuberculosis in the Emergency Department [Internet]. Am J Case Rep. 2020 Mar;21:e920393. [cited 2020 Nov 16] Available from: https://www.amjcaserep.com/abstract/index/idArt/920393

16 Basford JR. The Law of Laplace and its relevance to contemporary medicine and rehabilitation. Arch Phys Med Rehabil. 2002 Aug;83(8):1165-70.

17 Yorke E, Atiase Y, Akpalu J, Sarfo-Kantanka O, Boima V, Dey ID. The Bidirectional Relationship between Tuberculosis and Diabetes. Tuberc Res Treat. 2017;2017:1702578.

18 Collaborative framework for care and control of tuberculosis and diabetes. Geneva: World Health Organization; 2011. 
Case Reports in Acute Medicine
Case Rep Acute Med 2021;4:7-12 DOI: $10.1159 / 000513324$ (c) 2021 The Author(s).
www.karger.com/cra

Adlar and Anthony: Spontaneous Pneumothorax as a Complication in Concomitant Diabetic Ketoacidosis and Pulmonary Tuberculosis: A Case Report

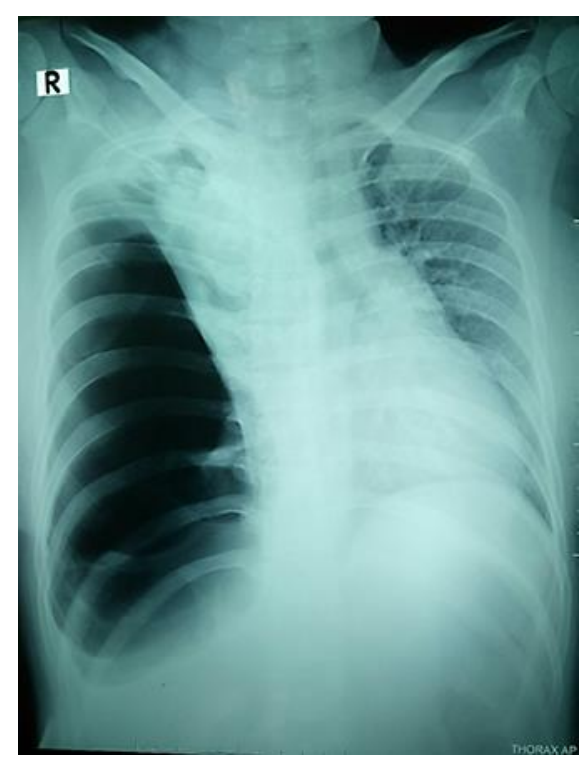

Fig. 1. Initial chest X-ray (anteroposterior view) showing the right pneumothorax and the collapsed right lung parenchyma with inhomogeneous opacity noted in the upper lobe of the right lung.

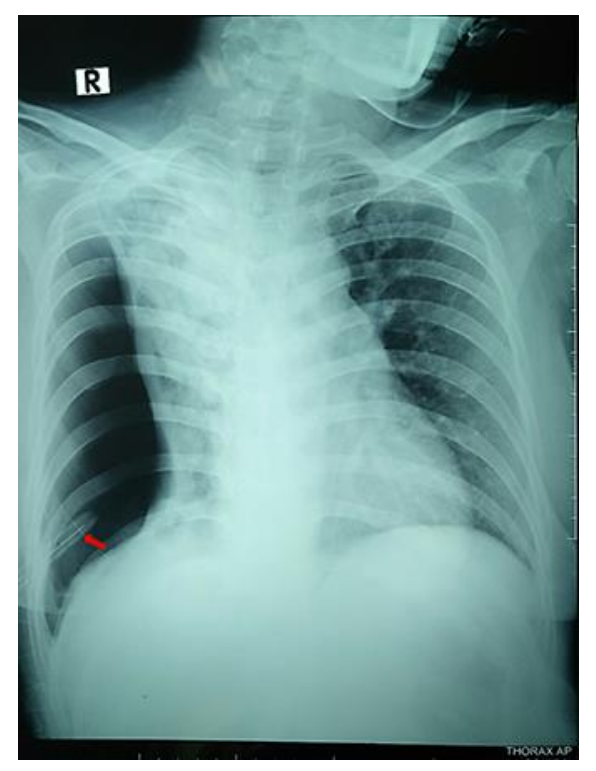

Fig. 2. Subsequent chest X-ray following placement of chest tube drainage (red arrow) showing an improvement of the pneumothorax.

\section{Karger'"}

